bolism of I33 I Calories. The regression formula gives 1486 Calories \pm 102 ; the surface rule 1620 Calories \pm 130 .

Neither prediction is close to the truth, but that of the regression equation is decidedly superior. On the whole, there is no doubt that the regression method is preferable, and that the tables provided by the authors are of value. In general, however, the difference is not such as to give rise to any apprehen. sions that the use heretofore made of the surface rule has led to practical inconvenience. Prof. Lusk recently wrote:- "For the study of metabolism processes it is certainly most fortunate that the unit of surface area eliminates the same amount of heat in the normal adult within so per cent. of a determined average. The reason is not clear.'

This remark is not invalidated by Drs. Benedict and Harris's results, although they have provided a somewhat superior criterion. It is proper to notice this point, as our authors are a little too prone to lecture their physiological colleagues upon the real meaning of scientific "laws," and, as we think, exaggerate the importance which the surface "law" assumes in the minds of those who have employed it as a convenient working rule.

Space would have been saved and the statistical results and methods might have been brought to a sharper focus had a number of sententious generalities been omitted. An instance occurs on p. I48. The authors properly remark that surface must be less variable than mass (when Meeh's formula is used), and imply that it is a direct arithmetical consequence that heat per surface unit is less variable than heat per mass unit. This really needed further investigation. The coefficient of variation of an index is a function not only of the coefficients of variation of its constituents, but also of their correlation; the substitution for one constituent of another less variable constituent might not reduce the variability of the index were the correlation also greatly reduced. In the present case the two correlations are nearly equal, and the authors could have actually made their point more securely had they explained the theory of the matter more fully.

Were physiologists really so ill-acquainted with statistical methods as the authors hint, the remarks on p. I6 with respect to the "probable error" of the mean of a sample of four might be dangerous. But we think that British physiologists are quite alive to the importance of biometric methods, sufficiently so to congratulate Drs. Benedict and Harris upon the conclusion of a laborious task which has yielded results of appreciable value to other students of metabolism.

The second volume describes two series of experiments upon squads of college students, originally twelve in each squad. In squad $\mathrm{A}$, diet providings approximately 2500 Calories and I3 grams of nitrogen was maintained for four months; in sauad B, a still lower diet, yielding about 9 grams of nitrogen and I500 Calories, was used for three weeks. The former squad lost on the average 12 per cent. of the initial body-weight, and the basal metabolism per square metre per twenty-four hours fell from 940 to 8 I7 Calories. Squad B lost 6.5 per cent. of the average body-weight, and the basal metabolism also declined considerably. The urinary excretion of nitrogen in both series was not so variable as might have been expected, and did not decline, pari passu, with the diminished intake. By the end of the experiment on squad $\mathrm{A}$, an average loss of 175 grams of nitrogen (based on nine men continuously observed) was inferred.

In the course of the experiments intervals of uncontrolled feeding occurred, viz. during the Thanksgiving celebrations, November 29 to December 2, 1917, NO. 2624 , VOL. IO4] and during the Christmas holidays, December 20, 1.917, to January 6, igr8. On alternate Sundays the diet was usually uncontrolled. A very large number of anthropometric, physiological, and psychological measurements were made upon these men. In addition to the decline of basal metabolism above noted, both pulse-rate and blood-pressure diminished. Little objective evidence of a decrease of physical efficiency was obtained. The majority of the psychological tests pointed to a diminution of efficiency, or at least to a lack of improvement with practice. The students" college work, on the other hand, did not appear to suffer.

The value of this research, which yerifies upon a relatively large scale the practicability of diminishing both the rate of metabolism and the quota of body nitrogen by a simple reduction of intake, should be appreciated by scientific clinicians, while many issues of physiological interest are raised and lines of advance suggested to the pure physiologist, especially in connection with the study of levels of nitrogenous metabolism

As a contribution to the science and art of national dietetics, this elaborate-one might almost say overelaborate-study is not of so much importance. It is shown that a great reduction, both of available energy and protein, may be borne for some months by healthy adults without either immediate breakdown or sign of enduring deterioration; these are facts which involuntary experiment on a vast scale had already demonstrated. The correlation between variations of nutrition and of resistance to infection, which "common sense" has postulated and which the vital statistics of Europe seem to substantiate, must engage the attention of future investigators; at present an adequate experimental technique is lacking. We do not think that Dr. Benedict and his associates have obtained any results either invalidating the general conclusions expressed by the Food (War) Committee of the Roval Society or filling up lacunæ in our knowledge of the general subject shown by that committee to exist. The experimental and statistical study of national dietetics is still in its infancy. $M . G$.

\section{ISOSTATIC COMPENSATION IN THE EARTH'S CRUST.}

TWO articles on isostasy by the late Prof. Joseph Barrell, which appeared in the American Journal of Science for October, 1919, contain what may be regarded as his mature views on the subject. The first, entitled "The Nature and Bearings of Isostasy," was a summary of six lectures delivered by Prof. Barrell at Columbia University in 19J6; it gives a general account of the theory of isostatic compensa. tion, and of the methods of investigation which have led to the recognition of the phenomenon. The second article, "The Status of the Theory of Isostasy," was written just before the author's death; it vindicates the theory as to attacks which have been made on it by MacMillan and others, and describes the various views which are held as to the degree of perfection of isostatic balance existing in Nature. Hayford's general conclusion is maintained: that surface inequalities of contour and mass are accompanied by inverse inequalities of density beneath the surface, so that at a depth of about $120 \mathrm{~km}$. equal areas have equal masses superposed; but a view different from Hayford's is taken as to the exactness of this compensation.

Havford estimated the greatest departure from com. pensation as being $250 \mathrm{ft}$. above or below the level for perfect balance over an area of one square degree on 
the earth. Other geodesists consider that the deviation is much less than this, even when the areal extent is smaller; Sir S. G. Burrard, for instance, at the recent discussion on isostasy before the Royal Astronomical Society (Observatory, December, I9r9), suggested that so small a body as the Great Pyramid might be compensated. Prof. Barrell, on the other hand, while admitting that the larger relief of the earth is compensated for with considerable exactness, contends that over limited areas there are large deviations-amounting to $1000 \mathrm{ft}$. over an area 200 miles in diameter (about $3^{\circ}$ ), or even more. $\mathrm{He}$ regards the upper part of the earth's crust as sufficiently strong to sustain uncompensated loads of this amount, the vertical magnitude of the departure being, of course, inversely proportional to its areal extent; it can thus support individual mountains or limited ranges, as well as erosion features of considerable magnitude, such as the Nile and Niger deltas. Under greater and more widely extended loads, however, the crust is supposed to bend in gentle curves involving but little crustal stress; this bending is accompanied by yielding in a lower, weaker layer, which brings about isostatic compensation.

The question at issue is largely one of fact, which can be settled by observation; e.g. if pendulum observations show that the Nile deposits are compensated in the crust, the result will confirm the views of the extreme isostasists, that continuous adjustment goes on when the surface load changes over a comparatively small area. The manner of this adjustment, however, has not yet been made clear, and Prof. Barrell's picture of the process is more easy to conceive. On the other hand, Sir S. G. Burrard has shown recently that the alluvium in the Gangetic trough at the foot of the Himalayas is compensated for. It is much to be regretted that Prof. Barrell's death deprives us of his interpretation of this result.

\section{DEFENSIVE SCIENCE IN GAS WARFARE.}

THE prizes and certificates gained by students at the Sir John Cass Technical Institute, Aldgate, were distributed by Lt.-Col. P. S. Lelean, professor of hygiene, Royal Army Medical College, on the evening of Tuesday, February 3, when the chair was taken by the Rev. J. F. Marr, who has succeeded Sir Thomas Elliott, K.C.B., as chairman of the governing body.

Following the distribution, Col. Lelean gave an address on "Defensive Science in Gas Warfare," in which he described the preventive measures that had been adopted to meet its onset and evolution. After referring to the initial attack on April 23, I9I5, when the civilised world was aroused to just anger by the news that the Germans had broken their pledged word in respect to the use of poisons as a means of injuring the enemy, Col. Lelean dealt with the means of protection first adopted in the form of pads soaked in sodium thiosulphate, of which no fewer than 08,000 were distributed to the Front within sixty hours of the attack, 300,000 within a week, and 2,000,000 within a month-a truly notable achieve. ment, which was rendered possible only by the combined efforts of men of science, manufacturers, and voluntary helpers.

With the recognition of gas attacks as an estab. lished adjunct of modern warfare, this temporary device was succeeded by the more efficient protective appliances which were called for by the advent of toxic, paralysins, and lachrvmatory gases such as carbonyl chloride. hydrocyanic acid, and chloropicrin, which culminated first in the adoption of the " $\mathrm{P}$ " helmet, of which nearly $27,000,000$ were issued between July, IgI5, and the final withdrawal in February, I9I8, in favour of the now well-known "box-respirator.",

$A$ full description was given of the great difficulties that were met with stage by stage during the development of these protective appliances, especially in respect to the need for the complete absorption of the small percentages of the poison gases concerned, together with the fundamental requirements of comparative ease of breathing and exhalation.

Col. Lelean paid a special tribute to the outstanding services of Sir William Horrocks and to the late Col. E. F. Harrison in this connection; also to the many scientific helpers with whom they were associated, and particularly to the gallantry and devotion to duty of the small band of scientific workers who had served under him and upon whom had devolved the practical testing of the efficiency of the many devices which were experimented with in a "lethal chamber" before their issue to the fighting forces could be justified.

In speaking of the helpful war-work contributed by the staff of the Sir John Cass Technical Institute, Col. Lelean expressed the view that it was to such institutes that the nation looked in its hour of scientific need, and had not looked in vain; and that it is to such institutes also that, with an ever-increasing appeal, we shall have to look for victory in the future strife of industrial competition, which can be won only by superior technical skill.

\section{VISUAL TESTS FOR MOTOR-DRIVERS.}

THE Council of British Ophthalmologists, realising the importance of submitting chauffeurs and other drivers of motor vehicles to some visual tests, appointed a committee to consider the question. Its report is divided into five parts:-(I) The existing conditions under which licences are at present granted; (2) the number of accidents occasioned annually in London by mechanically propelled vehicles; (3) the various kinds of visual defects in motor-drivers from which accidents may arise; (4) proposed scheme of visual testing for licences; and (5) summary of recommendations. The subject is complicated by the following facts. There are two licensing authorities, the county or borough councils and the police authorities. The requirements vary according to the type of vehicle, e.g. private cars, commercial cars, omnibuses, taxi-cabs, and tramcars. The total number of applicants for licences makes it impracticable to submit every one to a satisfactory sight test. The council's chief recommendations are :-

"That special sight-test certificates for drivers of motor vehicles be instituted, and granted to applicants whose sight has been tested by ophthalmic surgeons appointed for the purpose, these certificates to be of three grades: Grade A, certifying the holder's visual capacity to drive any kind of motor vehicle; Grade B. certifying the holder's visual capacity to drive any kind of motor vehicle other than a motor-omnibus or tramcar; and Grade C, certifying the holder's visual capacity to drive a motor-tramcar.

"For Grade A Certificate.-(I) Every applicant, in addition to manifesting his ability to steer a motor-car satisfactorily in daylioght, should be required, in a trial trip at night, to show himself capable of driving in dim light and under varying degrees of illumina. tion. (2) In an examination by an ophthalmic surgeon he should show: (a) Visual acuity of $6 / 9$ in one eye and $6 / 24$ in the other eye without the aid of glasses: (b) a full ficld of vision in each eye; $(c)$ no manifest squint; and $(d)$ no double vision.

"For Grade B Certificate.-.-(I) Every applicant, in addition to manifesting his ability to steer a motor-car NO. 2624, VOL. IO4] 